\title{
Omalizumab, an anti-immunoglobulin E antibody: state of the art
}

\author{
This article was published in the following Dove Press journal: \\ Drug Design, Development and Therapy \\ 7 February 2014 \\ Number of times this article has been viewed
}

\section{Cristoforo Incorvaia' \\ Marina Mauro ${ }^{2}$ \\ Marina Russello² \\ Chiara Formigoni ${ }^{3}$ \\ Gian Galeazzo Riario- \\ Sforza' \\ Erminia Ridolo 4}

'Allergy/Pulmonary Rehabilitation, Istituti Clinici di Perfezionamento Hospital, Milan, Italy; ${ }^{2}$ Allergy Unit, ${ }^{3}$ Scientific Library, Sant'Anna Hospital, Como, Italy; ${ }^{4}$ Department of Clinical and Experimental Medicine, University of Parma, Parma, Italy
Correspondence: Cristoforo Incorvaia Allergy/Pulmonary Rehabilitation, ICP Hospital, Via Bignami I, 20126 Milan, Italy Tel +3902 57993289

Fax +3902 57993759

Email cristoforo.incorvaia@gmail.com
Abstract: A large number of trials show that the anti-immunoglobulin (Ig) E antibody omalizumab is very effective in patients with severe allergic asthma. This is acknowledged in consensus documents. The drug also has a good safety profile and a pharmacoeconomic advantage due to a reduction in the number of hospitalizations for asthma attacks. In recent years, some studies have shown that omalizumab is effective also in nonallergic asthma. Effects on the complex signaling mechanisms leading to activation of effector cells and to mediator release may account for this outcome. Indeed, omalizumab has been reported to be effective in a number of IgE-mediated and non-IgE-mediated disorders. Concerning the former, clinical efficacy has been observed in rhinitis, allergic bronchopulmonary aspergillosis, latex allergy, atopic dermatitis, allergic urticaria, and anaphylaxis. In addition, omalizumab has been demonstrated to be able to prevent systemic reactions to allergen immunotherapy, thus enabling completion of treatment in patients who otherwise would have to stop it. Concerning non-IgE-mediated disorders, omalizumab has been reported to be effective in nasal polyposis, autoimmune urticaria, chronic idiopathic urticaria, physical urticaria, idiopathic angioedema, and mastocytosis. Current indications for treatment with omalizumab are confined to severe allergic asthma. Consequently, any other prescription can only be off-label. However, it is reasonable to expect that the use of omalizumab will be approved for particularly important indications, such as anaphylaxis, in the near future.

Keywords: hypersensitivity, immunoglobulin E, anti-IgE, omalizumab, asthma, atopic dermatitis, anaphylaxis, urticaria, mastocytosis

\section{Introduction}

Among the human antibodies, the immunoglobulin E ( $\operatorname{IgE}$ ) antibodies were the last class to be discovered, due to their very low blood concentrations. ${ }^{1}$ Soon after their discovery, an in vitro test was introduced for measuring $\mathrm{IgE}$ that helped greatly to improve our understanding of allergic disease. ${ }^{2}$

IgE plays a central role in the pathophysiology of allergic disease. Once IgE reaches the bloodstream, it binds to the high-affinity IgE receptor (FceRI) on the surface of mast cells and basophils and, upon contact with a specific allergen, induces the release of pharmacologically active mediators stored in the granules of these cells, resulting in clinical manifestations of type I hypersensitivity. ${ }^{3}$ The ability to treat IgE-mediated diseases with an anti-IgE antibody was theorized back in the 1970s with the experiments of Kohler and Milstein. ${ }^{4}$ However, it took a long time to overcome the problems preventing use of anti-IgE antibodies in allergic subjects, such as humanization (from prototype mouse antibody), removal of anaphylactogenic potential (anti-IgE sera were used for decades to study the release of mediators of anaphylaxis from mast cells and 
basophils in vitro), and the risk of parasitic infections. The biological agent known as omalizumab finally proved to possess adequate characteristics for use in IgE-mediated allergies $^{5,6}$ as a result of its particular mechanism of action. This mechanism can be summarized as follows: binding to free $\mathrm{IgE}$, thus reducing cell-bound $\mathrm{IgE}$; reduction in high affinity FceRI receptors; reduction in mediator release; and reduction in allergic inflammation (Figures 1 and 2). The ideal condition for treatment with omalizumab is severe allergic asthma not controlled by conventional drug treatment at doses ranging from a minimum of $75 \mathrm{mg}$ up to $600 \mathrm{mg}$ (1-4 injections) every 2 weeks, according to total IgE levels, which must not exceed $600 \mathrm{IU} / \mathrm{mL}$ and actually range between 30 and $1,500 \mathrm{IU} / \mathrm{mL}$. Recently, the drug has been approved for therapeutic use in children aged 6-12 years. Adult and adolescent patients with $\mathrm{IgE}$ below $76 \mathrm{IU} / \mathrm{mL}$ and children with IgE below $200 \mathrm{IU} / \mathrm{mL}$ must have reactivity (RAST) to a perennial allergen before starting therapy (Tables 1-3). At the recommended dosage, omalizumab achieved a significant reduction in free $\operatorname{IgE}$ within 24 to 48 hours of the first subcutaneous administration and a significant reduction in clinical symptoms within a week. ${ }^{7}$ A large number of controlled studies have demonstrated the efficacy and safety of omalizumab in allergic asthma. The present review assesses further studies of omalizumab in asthma and new indications, including nonallergic disorders.

Regarding safety, the therapeutic use of omalizumab in clinical practice was at first restricted on account of the risk of anaphylactic reactions. This risk has been considerably reduced both by the introduction of a ready-to-use solution formulation of the drug and by experience following the

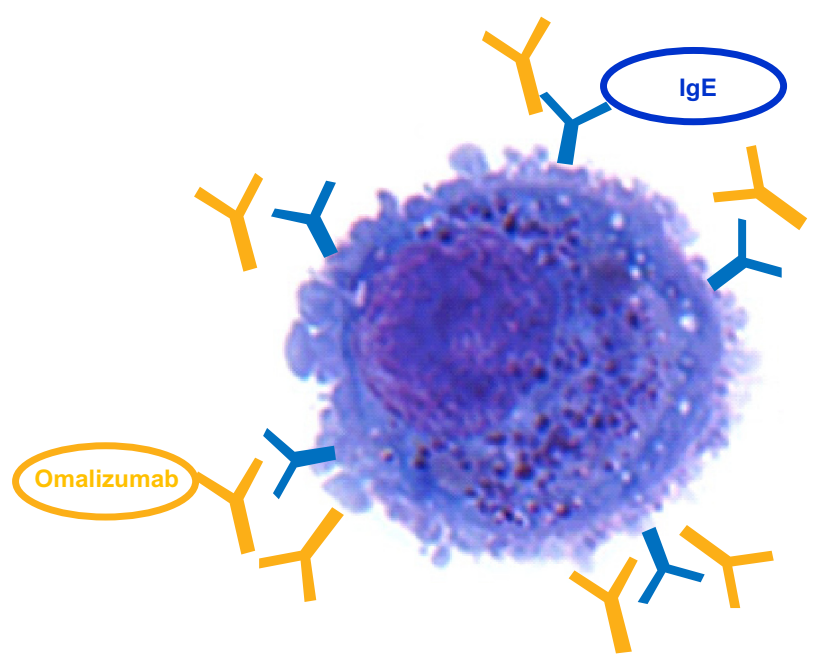

Figure I Omalizumab inhibits more than $96 \%$ of immunoglobulin $E$ (IgE) from binding to the high affinity receptor FceRI on mast cells and basophils. increase in exposed patient populations within the context of clinical studies and post-marketing surveillance initiatives.

A study ${ }^{8}$ analyzed the safety of omalizumab using data from completed clinical studies involving more than 7,500 patients with asthma, rhinitis, or related conditions treated for up to one year and data from a study of patients with severe allergic asthma treated for up to 4 years, as well as post-marketing safety data for omalizumab. The drug showed a good safety and tolerability profile. The incidence of anaphylaxis was $0.14 \%$ in omalizumab-treated patients and $0.07 \%$ in control patients. Post-marketing data, based on estimated exposure of 57,300 patients (June 2003 to December 2006), showed that the frequency of anaphylaxis attributed to omalizumab use was estimated to be at least $0.2 \%$. The incidence of anaphylaxis in the controlled studies (investigator-reported) was rare (omalizumab $0.14 \%$ versus control $0.07 \%$ ).

This rate is similar to the incidence of anaphylactic reactions for other drugs, such as oral penicillins, aspirin, and nonsteroidal anti-inflammatory drugs, ${ }^{9}$ as well as to the incidence and prevalence of anaphylaxis reported in the general omalizumab-free population (about $0.05 \%-2 \%$ ). ${ }^{10-12}$ Post-marketing data have also highlighted that anaphylaxis may occur not only after first administration of omalizumab, but also after subsequent administrations and after longer post-administration periods than those monitored in clinical trials. ${ }^{9}$

At present, the most interesting aspect is the high number of publications reporting the efficacy of omalizumab in a number of different diseases, including, unexpectedly, diseases that hitherto have been considered to be non-IgEmediated. This phenomenon is such that there is a current trend of using omalizumab as a probe to assess the role of IgE in human disease. ${ }^{13}$ However, it must be taken into account that the identification of new therapeutic activity for omalizumab does not allow its therapeutic use in that specific condition (except off-label usage), because the only approved indication at this time is severe perennial allergic asthma not controlled by conventional therapy.

\section{Omalizumab in asthma}

In 2006, a systematic Cochrane review analyzed the efficacy of omalizumab in allergic asthma based on data obtained from 14 placebo-controlled studies including a total of 3,143 patients. The results led the authors to draw the conclusion that omalizumab is effective. A significant number of patients were able to reduce their dose of inhaled steroids, which are the mainstay of asthma therapy, by more than $50 \%$ 


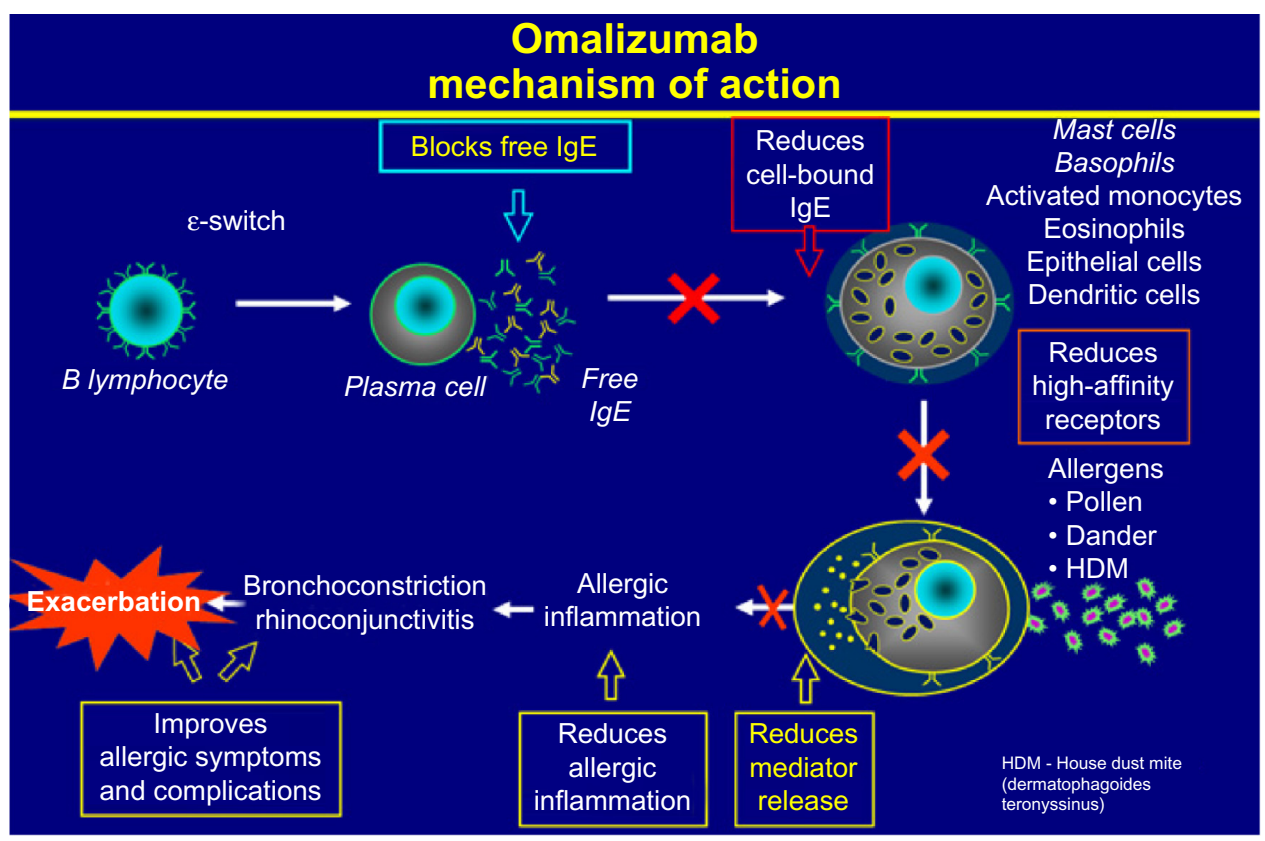

Figure 2 Mechanism of action of omalizumab.

Abbreviation: $\lg \mathrm{E}$, immunoglobulin $\mathrm{E}$.

or even discontinue them completely, with an odds ratio of 2.50 in both cases. ${ }^{14}$ Other trials were conducted in recent years and confirmed that omalizumab improves symptom control, reducing the frequency of asthma exacerbations and the need to use high doses of inhaled corticosteroids, thus fulfilling an important need in patients with moderate to severe asthma. ${ }^{15}$ In particular, a recent trial by Busse et al demonstrated that omalizumab significantly reduces disease exacerbations and hospitalizations compared with placebo in inner city children with asthma. ${ }^{16}$

Useful information in terms of current practice is also provided by real-life studies, which are certainly different from the environment of controlled trials. A Belgian study of 158 asthmatic patients with frequent symptoms

Table I Conversion from dose to number of vials, number of injections and total injection volume for each administration

\begin{tabular}{|c|c|c|c|c|}
\hline \multirow{2}{*}{$\begin{array}{l}\text { Dose } \\
\text { (mg) }\end{array}$} & \multicolumn{2}{|c|}{ Number of vials } & \multirow{2}{*}{$\begin{array}{l}\text { Number of } \\
\text { injections }\end{array}$} & \multirow{2}{*}{$\begin{array}{l}\text { Total injection } \\
\text { volume }(\mathrm{mL})\end{array}$} \\
\hline & $75 \mathrm{mg}^{\mathrm{a}}$ & $150 \mathrm{mg}^{\mathrm{b}}$ & & \\
\hline 75 & $\mathrm{I}^{\mathrm{c}}$ & 0 & 1 & 0.6 \\
\hline 150 & 0 & 1 & I & 1.2 \\
\hline 225 & $I^{c}$ & 1 & 2 & 1.8 \\
\hline 300 & 0 & 2 & 2 & 2.4 \\
\hline 375 & $I^{c}$ & 2 & 3 & 3.0 \\
\hline 450 & 0 & 3 & 3 & 3.6 \\
\hline 525 & $I^{c}$ & 3 & 4 & 4.2 \\
\hline 600 & 0 & 4 & 4 & 4.8 \\
\hline
\end{tabular}

Notes: ${ }^{a} 0.6 \mathrm{~mL}=$ maximum delivered volume per vial (Xolair $75 \mathrm{mg}$ ). ${ }^{b} \mathrm{l} .2 \mathrm{~mL}=$ maximum delivered volume per vial (Xolair $150 \mathrm{mg}$ ). ${ }^{\mathrm{c}}$ Or use $0.6 \mathrm{~mL}$ from a $150 \mathrm{mg}$ vial. and exacerbations in the previous year, despite treatment with high doses of inhaled corticosteroids and long-acting $\beta 2$-agonists, showed that treatment with omalizumab was associated with an absence of exacerbations in more than $65 \%$ of patients after one year, as well with improved quality of life in $84 \%$ of patients. ${ }^{17}$ The clinical benefit in real-life conditions, including a significant reduction in emergency department visits and hospitalizations, was confirmed in recent studies in adults ${ }^{18-20}$ and children. $^{21}$

Further progress was made by conducting a placebocontrolled trial in 41 adult patients with severe, nonatopic, refractory asthma despite optimal treatment. The change in FceRI expression on blood basophils and plasmacytoid dendritic cells was evaluated after 16 weeks, along with the impact of omalizumab on lung function and clinical variables. Compared with placebo, treatment with omalizumab resulted in a statistically significant reduction in FceRI expression on basophils and plasmacytoid dendritic cells $(P<0.001)$ and an overall increase in forced expiratory volume in one second compared with baseline. The authors concluded that omalizumab regulates FceRI expression negatively in patients with severe nonatopic asthma, as it does in severe atopic asthma. ${ }^{22}$ This accounts for a possible role of $\operatorname{IgE}$ in nonatopic asthma. A potential explanation for this outcome was provided by Barnes, who suggested that asthmatic inflammation, which is characterized by a predominance of Th2 lymphocytes with the related cytokine profile, 
Table 2 Administration every 4 weeks

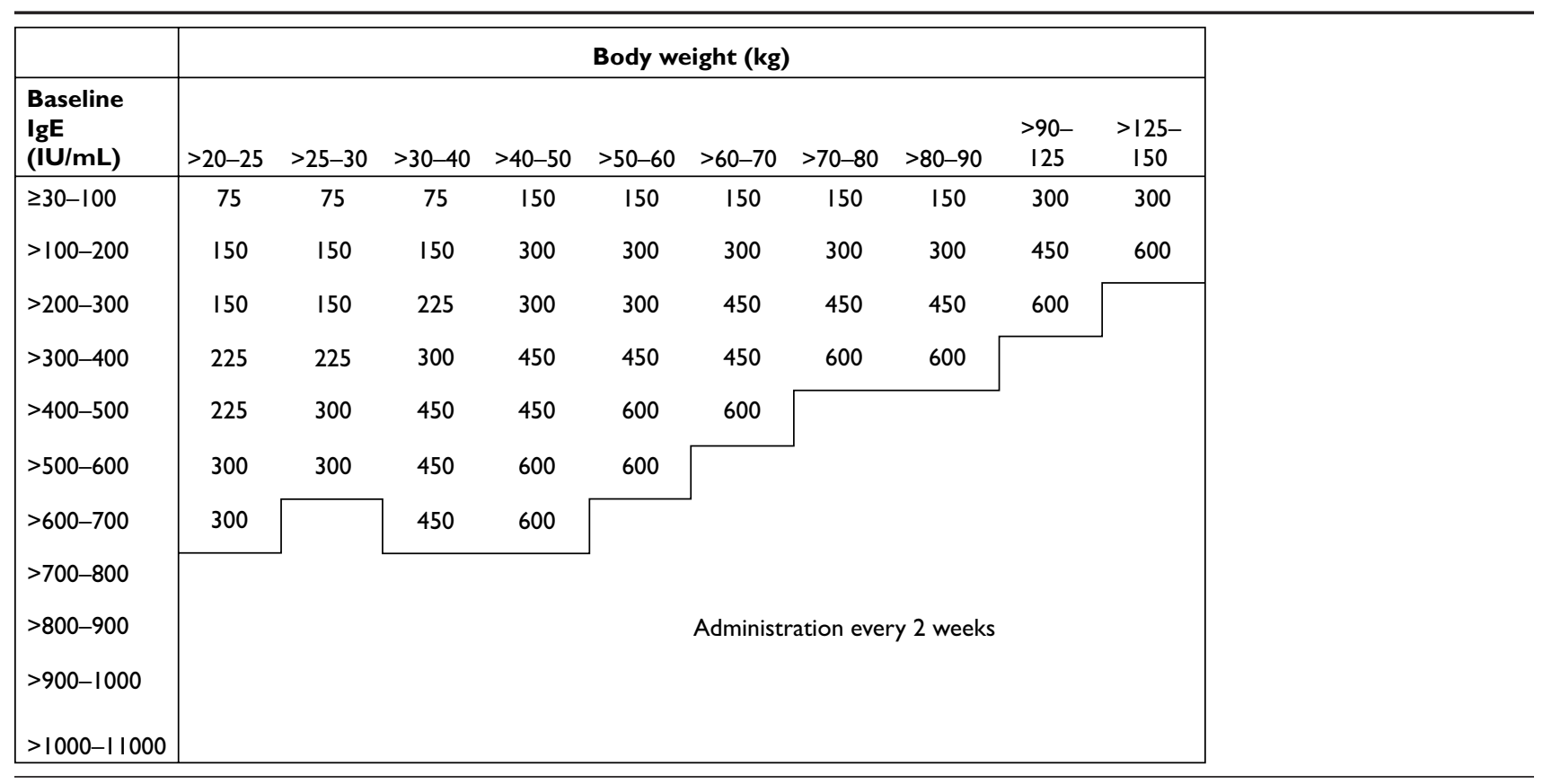

Note: Xolair doses (milligrams per dose) administered by subcutaneous injection every 4 weeks.

Abbreviation: IgE, immunoglobulin $\mathrm{E}$.

by mast cell activation and eosinophilic infiltration can be triggered by superantigens. Such superantigens include Staphylococcus aureus antigens, which are able to activate production of polyclonal IgE (including specific IgE against the same superantigens) locally in the respiratory tract. ${ }^{23} \mathrm{On}$ the other hand, the role of superantigens was previously suggested by Marone et al concerning allergic disorders in general. ${ }^{24}$ Further support for these additional effects of omalizumab has been provided by studies showing that its action extends to the complex signaling mechanism, leading to activation of effector cells and release of mediators. In fact, treatment with omalizumab can modify the expression of Syk, a tyrosine kinase of central importance in the signaling mechanism, which leads to the final opening of calcium channels and degranulation, ${ }^{25}$ as well as to modulation of the FceRI- $\beta / \alpha$ ratio. ${ }^{26}$

Interestingly, the effectiveness of omalizumab was also recently reported in patients with severe occupational asthma caused by both high and low molecular weight compounds, with most treated patients being able to continue their activity at the same workplace. ${ }^{27}$

An important step forward concerns a matter for which no information has been available, ie, duration of treatment. A follow-up study by Nopp et al showed that, after 6 years of treatment, most patients had (surprisingly, according to the authors) mild and stable asthma in the 3 ensuing years and at the same time showed downregulation of the sensitivity of basophils to specific allergens. ${ }^{28}$ This supports the role of omalizumab as a therapeutic agent for nonspecific immunotherapy. In fact, omalizumab acts on IgE regardless of allergen specificity, while specific immunotherapy (SIT) acts exclusively on allergen-specific IgE. This was the first indication that a 6-year course of treatment is adequate, as is the case for SIT, ${ }^{29}$ but this finding must be confirmed by further studies.

The fact that omalizumab continues to work after discontinuation indicates additional benefit in terms of cost-effectiveness, which, despite the high cost of the drug, was clearly demonstrated by recent studies. ${ }^{30-32}$ In particular, in the latest study, it was found that in the one year prior to omalizumab therapy the per-person rate of asthma exacerbations was 3.39 compared with 1.07 in the year of taking omalizumab. Using the pharmacoeconomic index of quality-adjusted life-years (QALYs), the discounted incremental lifetime additional costs for omalizumab were $€ 55,865$ for 1.46 additional QALYs, resulting in $€ 38,371$ per QALY. This supports the claim that the cost-effectiveness ratio related to achievement of fewer exacerbations in the omalizumab-treated asthma population is attractive. ${ }^{33}$ The outcome of the significant reduction in asthma exacerbations is in agreement with our current practice; in our patients, the mean numbers of emergency department visits and hospitalizations were found to be 5.6 and 3.2, respectively, before treatment compared with 1.2 and 0.8 after treatment with omalizumab. 
Table 3 Administration every 2 weeks

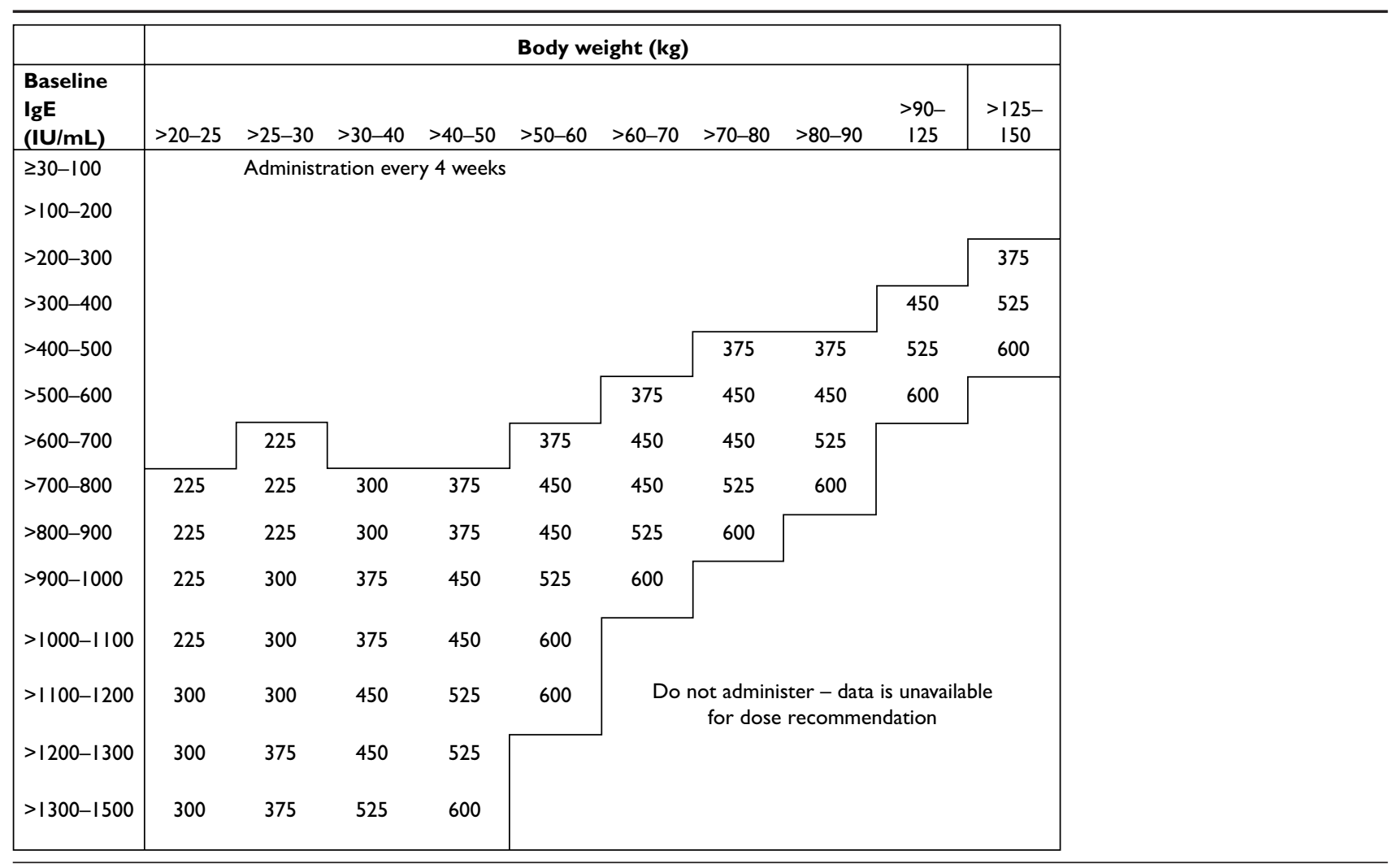

Note: Xolair doses (milligrams per dose) administered by subcutaneous injection every 2 weeks.

Abbreviation: IgE, immunoglobulin $\mathrm{E}$.

The persistence of the effects of omalizumab may be related to the ability of the drug to curtail airway remodeling in patients with asthma. In a study aimed at assessing the effects of omalizumab on airway wall thickness by computed tomography, treatment with omalizumab significantly $(P<0.01)$ decreased the airway wall area (corrected for body surface area, WA/BSA), percentage wall area (WA\%), wall thickness $[(\mathrm{T}) / \sqrt{ } \mathrm{BSA}]$, and luminal area [(Ai)/BSA] of the right apical bronchial segments, whereas conventional therapy resulted in no change..$^{34} \mathrm{~A}$ significant mean reduction in thickness of the reticular basement membrane and eosinophil infiltration in bronchial biopsies from patients with severe persistent allergic asthma was recorded after one year of omalizumab treatment using light microscopic image analysis. ${ }^{35}$ This evidence suggests that omalizumab may have a role in modifying the course of the disease by curtailing airway remodeling during severe persistent allergic asthma.

\section{Further therapeutic activity of omalizumab: off-label indications Allergic rhinitis and nasal polyposis}

In view of the close relationship between allergic rhinitis and asthma, the efficacy of omalizumab in the treatment of concomitant rhinitis in patients with asthma was to be expected. ${ }^{36,37}$ A parallel response of the two allergic reactions was shown, and in one trial the odds ratio for a positive effect on rhinitis corresponded to 3.56 , ie, the probability was three and a half times higher in subjects with improvement of asthma compared with nonresponders. ${ }^{38}$

The effect of omalizumab on nasal polyps is less obvious, because polyposis often occurs in nonallergic subjects. However, in nasal polyposis, local activation of polyclonal IgE similar to that reported previously for intrinsic asthma may occur. $S$. aureus, the enterotoxins of which act as superantigens, also plays an important role in this condition. Verbruggen et al proposed a "proof-of-concept" trial with omalizumab in nasal polyposis, which, in the event of a positive response, would pave the way for treatment of this disease using anti-IgE agents. ${ }^{39}$ The results of the trial are pending. However, favorable results are already available from a pilot study conducted in the US, which included a group treated with omalizumab and a control group. ${ }^{40}$ Collectively, this trial shows a direct relationship between severity of nasal polyposis and pretreatment total serum IgE levels, with no differences between the groups with regard to their total serum IgE levels, sinus computed tomography 
scores, and endoscopically determined nasal polyposis scores assessed preoperatively. Compared with preoperative values, nasal polyposis scores were significantly improved in the anti-IgE group, whereas the control group showed no significant improvement.

\section{Allergic bronchopulmonary aspergillosis}

Allergic bronchopulmonary aspergillosis is caused by an excessive response of Th2 lymphocytes to Aspergillus fumigatus, a ubiquitous mold. Allergic bronchopulmonary aspergillosis develops in a small proportion of patients with asthma, but patients with cystic fibrosis may also be affected, suggesting that intrinsic host defects play a major role in susceptibility to this disease. ${ }^{41}$ The efficacy of omalizumab has been demonstrated in case reports ${ }^{42-44}$ and also in case series. ${ }^{45-47}$ The treatment was found to be efficacious with regard to clinical parameters for allergic bronchopulmonary aspergillosis and also had a steroid-sparing effect.

\section{Skin disorders}

The first skin disease in which omalizumab was assessed was atopic dermatitis. Several reports on limited case series were published initially, ${ }^{48}$ followed by a pilot study in 21 subjects. ${ }^{49}$ In the pilot study, patients were stratified according to IgE level (very high, $>700 \mathrm{IU} / \mathrm{mL}$; high, 186-700 IU/mL; normal, $\leq 185 \mathrm{IU} / \mathrm{mL}$ ), with an average pretreatment level corresponding to $1,521 \mathrm{IU} / \mathrm{mL}$. All patients showed significant improvement in their clinical scores for atopic dermatitis. In a placebo-controlled trial, omalizumab reduced free serum IgE levels, lowered surface IgE and FceRI expression on mononuclear cells, reduced the saturation of FceRI with IgE, increased the number of free FceRI, and lowered the number of IgE+, but not the number of FceRI+ cells in skin. ${ }^{50}$ The in vivo relevance of these results is shown by the increased threshold allergen concentration required to trigger a type I hypersensitivity reaction on skin testing. Treatment with omalizumab led to improved atopy patch test results in individual patients, ie, an eczematous reaction upon epicutaneous allergen challenge. The interference with immediate and delayed skin tests implies that a therapeutic benefit for omalizumab would be seen in patients with acute rather than chronic forms of the disease.

Urticaria is a skin disorder sustained by a number of mechanisms that do not usually include IgE mediation. Therefore, the positive results obtained in this condition were the most surprising: an initial report of complete resolution of a case of cold urticaria with omalizumab ${ }^{51}$ was followed by therapeutic success in urticaria caused by heat ${ }^{52}$ and delayed pressure, ${ }^{53}$ as well as in solar ${ }^{54}$ and cholinergic ${ }^{55}$ urticaria. However, there are also negative reports in the latter two conditions. ${ }^{56,57}$ One study also reported the efficacy of omalizumab in subjects with angioedema classified as idiopathic. ${ }^{58}$

Within this context, omalizumab can be used as a probe to assess the relative importance of IgE-mediated mechanisms in the various clinical forms of urticaria/angioedema. From this point of view, the most important clinical application is chronic urticaria, including its idiopathic and autoimmune variants, which cover most cases. In a first report on three patients resistant to antihistamine therapy, one with low levels of total IgE, one with high levels, and one with high levels of both $\mathrm{IgE}$ antibodies and anti-IgE receptor antibodies, complete remission of urticaria was observed in two patients within a week and in the other within 6 weeks. ${ }^{59}$ In a study of autoimmune urticaria not controlled by antihistamines, including 12 patients with positive autologous serum skin and histamine release tests, all patients received omalizumab following 4 weeks of treatment with placebo, and showed significant improvement in clinical scores (complete resolution in seven cases), a significant decrease in consumption of drugs used for symptomatic relief, and improvement in quality of life, with only one patient not responding to treatment. ${ }^{60}$

A recent multicenter, randomized, double-blind, Phase III study evaluated the efficacy and safety of omalizumab in a large population of patients with moderate to severe chronic idiopathic urticaria, who remained symptomatic despite antihistamine therapy at the licensed doses; 323 patients received three doses of $75 \mathrm{mg}, 150 \mathrm{mg}$, or $300 \mathrm{mg}$, or placebo at 4-week intervals, followed by a 16 -week observation period. At week 12, the mean change from baseline in weekly itch severity score was $-5.1 \pm 5.6$ in the placebo group, $-5.9 \pm 6.5$ in the $75 \mathrm{mg}$ group $(P=0.46),-8.1 \pm 6.4 \mathrm{in}$ the $150 \mathrm{mg}$ group $(P=0.001)$, and $-9.8 \pm 6.0$ in the $300 \mathrm{mg}$ group $(P<0.001)$. The rate of adverse events was similar across the groups. These findings show that omalizumab reduces clinical symptoms and signs of chronic idiopathic urticaria in patients resistant to approved doses of antihistamines. ${ }^{61}$

Mastocytosis is another skin disease with systemic effects that has stimulated research on the role of omalizumab in prophylaxis of this condition. The first two studies reporting clinical efficacy suggested to the authors that omalizumab might inhibit the alleged stimulation of survival and accumulation of mast cells by $\operatorname{IgE}^{62}$ and downregulation of the FceRI receptor. ${ }^{63}$ It is well known that mastocytosis is a risk 
factor for severe, life-threatening reactions to Hymenoptera stings and also for reactions to venom immunotherapy. ${ }^{63}$ It was reported that omalizumab, albeit at high doses, is able to prevent the reactions to venom immunotherapy in patients with mastocytosis. ${ }^{64,65}$ Another report concerned a patient with indolent mastocytosis and a history of repeated anaphylactic episodes without any apparent cause. Following treatment with low doses of omalizumab (150 mg per month), the patient did not experience any further episodes of anaphylaxis, and showed a reduction in tryptase levels from 25.4 to $14 \mathrm{ng} / \mathrm{mL}$ and a decrease in basophil activation, as indicated by a decrease in mean fluorescence intensity from 120 to 22; such an index is correlated with a decrease in IgE, which occurs in all subjects given its biological role on the cell surface. ${ }^{66}$

\section{Food-related anaphylaxis}

In addition to its promising effects in mastocytosis, important effects were obtained for omalizumab in anaphylaxis induced by food, which is a major cause of fatal events related to hypersensitivity reactions ${ }^{67}$ A placebo-controlled trial tested the effects of anti-IgE therapy on reactions to peanuts, the dominant cause of food-related anaphylaxis in the US. ${ }^{6}{ }^{6}$ Eighty-four patients were randomized to receive 150,300 , or $450 \mathrm{mg}$ of omalizumab or placebo. The $450 \mathrm{mg}$ dose demonstrated superior efficacy, increasing the amount of peanut tolerated from $178 \mathrm{mg}$ (approximately half a peanut) to $2.8 \mathrm{~g}$ (about nine peanuts), thereby removing the risk of anaphylaxis due to inadvertent consumption of small amounts.

One of the most striking observations is the ability of omalizumab to prevent so-called idiopathic anaphylaxis (ie, caused by unidentified triggers). ${ }^{69,70}$ Another clinical form of anaphylaxis successfully prevented by omalizumab is exercise-induced anaphylaxis, ${ }^{71}$ which is a clinical syndrome (presenting as food-dependent or nonfooddependent) in which anaphylaxis occurs in conjunction with physical exercise and for which the pathophysiology is still uncertain. ${ }^{72}$

\section{Food allergy}

Food hypersensitivity is associated not only with anaphylaxis but also with a number of other clinical conditions. A recent study evaluated the efficacy of omalizumab in 22 patients receiving treatment for asthma who had concomitant food allergy. ${ }^{73}$ The average concentration of total IgE was $1,120 \mathrm{IU} / \mathrm{mL}$ and the culprit foods were fish, shellfish, eggs, peanuts, tree nuts, soy, and wheat. Clinical improvement in reactions was observed after the sixth dose of omalizumab, in particular in nine patients affected by angioedema with or without anaphylaxis, in eight patients with atopic dermatitis, in six patients with rhinosinusitis, and in three patients with urticaria. In another study of 14 patients with peanut allergy, clinical and cellular responses were assessed during treatment with omalizumab for 6 months. At baseline, all subjects underwent a double-blind, placebo-controlled oral food challenge and a skin prick test titration, with measurement of basophil histamine release in response to peanut exposure. Basophil histamine release was repeated at week 2 and then weekly until it decreased to less than $20 \%$ of baseline values. The oral food challenges and skin prick test titrations were repeated after reduction of basophil histamine release (or at week 8 if basophil histamine release did not decrease) and again at 6 months. Omalizumab induced a significant increase in the threshold dose for oral food challenge with peanuts causing allergic symptoms (from 80 to $6,500 \mathrm{mg}, P<0.01$ ); peanut-induced basophil histamine release was completely suppressed in five patients and reduced by ten-fold in nine patients; and after 6 months of treatment, a significant suppression in skin prick test titration was also observed. The fact that the clinical response to omalizumab occurred early during treatment when basophils, but not mast cells, were suppressed, suggests that basophils have a role in acute food reactions. ${ }^{74}$

Another clinical form of food allergy involves the gastrointestinal system, and includes food allergy with gastrointestinal eosinophilia. A case series of patients with eosinophilic gastroenteritis showed that a 16-week course of omalizumab achieved not only a reduction in symptoms, but also a reduction in eosinophil counts, amounting to $35 \%-45 \%$ in blood and to $60 \%-70 \%$ in the duodenum and antrum..$^{75}$ The same investigators performed a study aimed at determining whether anti-IgE therapy, by blocking facilitated antigen presentation in vivo, attenuates allergen-specific Th2 cell responses, but no significant difference in indices of T cell function was detected. ${ }^{76}$ Eosinophilic esophagitis is a disorder of increasing interest in which food allergens, as well as inhaled allergens, play a causative role. ${ }^{77}$ In one report, two patients with multiple food allergies and eosinophilic esophagitis were treated with omalizumab and showed significant improvement in symptoms, despite negligible histologic and endoscopic responses. ${ }^{78}$

\section{Other disorders}

There are case reports describing the efficacy of omalizumab in other disorders, including both IgE-mediated diseases 
and disorders of unknown pathogenesis. Latex allergy is clearly an IgE-mediated condition and may be associated with a variety of clinical manifestations, including asthma, rhinitis, urticaria, dermatitis, and anaphylaxis. ${ }^{79}$ In a placebocontrolled trial, 12 latex-allergic health care workers showed a reduction in conjunctival and cutaneous responses to latex after treatment with omalizumab. ${ }^{80}$

Atopic keratoconjunctivitis is a severe ocular disorder that can cause blindness. ${ }^{81}$ In an open-label trial, six patients treated with omalizumab showed improvement in ocular symptoms. ${ }^{82}$ This positive outcome is supported by a case report showing a marked reduction in the use of oral steroids. ${ }^{83}$ Hyper-IgE syndrome is reported as a possible further application; in one case report, treatment with $450 \mathrm{mg}$ of omalizumab every 2 weeks produced complete resolution of skin manifestations in a 26 -year-old woman. ${ }^{84}$ Once again, omalizumab proved to be effective in disorders unrelated to IgE-mediated hypersensitivity, such as interstitial cystitis, ${ }^{85}$ bullous pemphigoid, ${ }^{86}$ chronic rhinosinusitis, ${ }^{87}$ and aspirinexacerbated respiratory disease. ${ }^{88}$

\section{Combination of omalizumab and SIT}

It is easily understandable that the combination of SIT and omalizumab is "virtuous" in improving the tolerability profile and clinical results. ${ }^{89}$ These two aspects are obviously related to each other, because patients with adverse reactions to SIT are unlikely to have the same clinical benefit as those who tolerate the treatment. In fact, the cumulative dose received will inevitably be lower, and the concept of dose dependence regarding the effectiveness of SIT is not up for discussion..$^{90}$ A randomized, double-blind, placebo-controlled study of 248 patients treated with perennial allergens (house dust mite, cat and dog epithelium) confirmed these observations, showing that treatment with omalizumab was associated with significantly fewer asthmatic and systemic adverse reactions compared with placebo, and enabled achievement of the usual maintenance dose. ${ }^{91}$ Other studies have assessed safety in 221 children treated with SIT for seasonal allergy, also documenting an excellent tolerability profile (including local reactions to the vaccine) in patients treated with omalizumab ${ }^{92}$ and the superior efficacy of SIT in 140 patients of any age with seasonal allergy. ${ }^{93}$ In this case, the combination of omalizumab and SIT had significantly superior effects to SIT alone with regard to intensity of symptoms $(P=0.004)$, and achieved better control of asthma $(P=0.029)$ and improved quality of life $(P=0.029)$.
There are also studies of SIT with Hymenoptera venom. The effects of omalizumab in preventing adverse reactions to SIT in patients with mastocytosis have already been discussed, ${ }^{65}$ but another area of concern is the safety of SIT with bee venom, which is much less well tolerated than vespid venom. ${ }^{94}$ Several case reports have shown the ability to prevent anaphylactic reactions to SIT with bee venom, thus enabling immunization of patients. ${ }^{95-97}$ However, this was not possible in one case. ${ }^{98}$ The patient in question, who did not tolerate previous attempts with SIT and had a high level of specific IgE for bee venom, was treated with $300 \mathrm{mg}$ of omalizumab at monthly intervals for 6 months, starting with a rush schedule 2 weeks after the last administration. It is possible that a higher dose of omalizumab or administration of the drug closer to initiation of SIT could be protective.

On the whole, addition of omalizumab to SIT seems to be beneficial, but the cost of the drug is so high that this combination cannot be used routinely. However, use of omalizumab is warranted in patients with asthma that cannot be controlled by standard drug treatment (and thus excluded from SIT) and in patients unable to reach the maintenance dose of venom immunotherapy because of repeated adverse reactions.

\section{Conclusion}

An increasing number of omalizumab studies are providing new information on the role of IgE-mediated mechanisms in various diseases, which sometimes was totally unexpected because IgE was not known to be involved in their pathogenesis. However, at present, omalizumab is approved for therapeutic use only in allergic asthma not controlled by conventional therapy, so there is a discrepancy between the information available in new indications and actual applicability. Consequently, translating the new knowledge into actual treatment remains theoretical until the new indications are authorized. There is agreement among experts on some applications, such as anaphylaxis (both food-induced and idiopathic), chronic urticaria, and the combination of omalizumab with SIT in selected cases, which should all be considered to be new indications. ${ }^{99-102}$ Moreover, further evaluation of the efficacy of omalizumab in larger patient populations in clinical practice in any disorder should include an assessment of the economic impact of this agent, given that this aspect is very important for the regulatory agencies responsible for scientific evaluation and authorization of medicinal products. 


\section{Acknowledgment}

The authors thank Dr Donatella Tedeschi and Dr Alina Papetti from the Medical Department of Novartis Farma SpA, Origgio, Italy, for their cooperation and for providing figures 1 and 2.

\section{Disclosure}

The authors report no conflicts of interest in this work.

\section{References}

1. Bennich HH, Ishizaka K, Johansson SG, Rowe DS, Stanworth DF, Terry WD. Immunoglobulin E: a new class of human immunoglobulin. Immunology. 1968;15:323-324.

2. Wide L, Bennich H, Johansson SG. Diagnosis of allergy by an in-vitro test for allergen antibodies. Lancet. 1967;2:1105-1107.

3. Siraganian RP. Mechanisms of IgE-mediated hypersensitivity. In: Middleton E, Reed CE, Ellis EF, Adkinson NF, Yunginger JW, Busse WW, editors. Allergy. Principles and Practice. St Louis, MI: Mosby; 1993.

4. Kohler G, Milstein C. Continuous cultures of fused cells secreting antibody of predefined specificity. Nature. 1975;256:495-497.

5. Jardieu PM, Fick RBJ. IgE inhibition as a therapy for allergic disease. Int Arch Allergy Immunol. 1999;118:112-115.

6. Schulman ES. Development of a monoclonal anti-immunoglobulin E antibody (omalizumab) for the treatment of allergic respiratory disorders. Am J Respir Crit Care Med. 2001;164:S6-S11.

7. Milgrom H, Berger W, Najak A, et al. Treatment of childhood asthma with anti-immunoglobulin E antibody (omalizumab). Pediatrics. 2001;108:E36.

8. Corren J, Casale TB, Lanier B, Buhl R, Holgate S, Jimenez P. Safety and tolerability of omalizumab. Clin Exp Allergy. 2009;39: 788-797.

9. Hendeles L, Sorkness CA. Anti-immunoglobulin E therapy with omalizumab for asthma. Ann Pharmacother. 2007;41: 1397-1410.

10. De Bisschop MB, Bellou A. Anaphylaxis. Curr Opin Crit Care. 2012;18:308-317.

11. Simons A. Real-life effectiveness of omalizumab in patients with severe persistent allergic (IgE-mediated) asthma at a single UK hospital. Am J Respir Crit Care Med. 2010;181:A1336.

12. Worm M, Babina M, Hompes S. Causes and risk factors for anaphylaxis. J Dtsch Dermatol Ges. 2013;11:44-50.

13. Mauro M, Incorvaia C, Formigoni C, Elia R, Russello M, Pellegrino D. The anti-IgE antibody omalizumab as a probe to investigate the role of IgE in pathology. Panminerva Med. 2012;54: 305-312.

14. Walker S, Monteil M, Phelan K, Lasserson TJ, Walters EH. Anti-IgE for chronic asthma in adults and children. Cochrane Database Syst Rev. 2006;2:CD003559.

15. D’Amato G, Perticone M, Bucchioni E, Salzillo A, D'Amato M, Liccardi G. Treating moderate-to-severe allergic asthma with anti-IgE monoclonal antibody (omalizumab). An update. Eur Ann Allergy Clin Immunol. 2010;42:135-140.

16. Busse WW, Morgan WJ, Gergen PJ, et al. Randomized trial of omalizumab (anti-IgE) for asthma in inner-city children. $N$ Engl J Med. 2011;364:1005-1015.

17. Brusselle G, Michils A, Louis R, et al. Real-life effectiveness of omalizumab in patients with severe persistent allergic asthma: the PERSIST study. Respir Med. 2009;103:1633-1642.

18. Cazzola M, Camiciottoli G, Bonavia M, et al. Italian real-life experience of omalizumab. Respir Med. 2010;104:1410-1416.

19. Barnes N, Menzies-Gow A, Mansyr AH, et al. Effectiveness of omalizumab in severe allergic asthma: a retrospective UK real world study. J Asthma. 2013;50:529-536.
20. Grimaldi-Bensouda L, Zureik M, Aubier M, et al. Does omalizumab make a difference to the real-life treatment of asthma exacerbations? Results from a large cohort of patients with severe uncontrolled asthma. Chest. 2013;143:398-405.

21. Deschildre A, Marguet C, Salleron J, et al. Add-on omalizumab in children with severe allergic asthma: a one year real life survey. Eur Respir J. March 21, 2013. [Epub ahead of print.]

22. Garcia G, Magnan A, Chiron R, et al. A proof of concept randomized controlled trial of omalizumab in patients with severe difficult to control nonatopic asthma. Chest. 2013;144:411-419.

23. Barnes PJ. Intrinsic asthma: not so different from allergic asthma but driven by superantigens? Clin Exp Allergy. 2009;39:1145-1151.

24. Marone G, Rossi FW, Detoraki A, et al. Role of superallergens in allergic disorders. Chem Immunol Allergy. 2007;93:195-213.

25. Luskova P, Draber P. Modulation of the Fcepsilon receptor I signaling by tyrosine kinase inhibitors. Search for therapeutic targets of inflammatory and allergy diseases. Curr Pharm Des. 2004;10: $1727-1737$.

26. Zaidi AK, Saini SS, Macglashan DW. Regulation of Syk kinase and FcRbeta expression in human basophils during treatment with omalizumab. J Allergy Clin Immunol. 2010;125:902-906.

27. Lavaud F, Bonniaud P, Dalphin JC, et al. Usefulness of omalizumab in the patients with severe occupational asthma. Allergy. 2013;68: 813-815.

28. Nopp A, Johansson SG, Adedoyin J, et al. After 6 years with Xolair; a 3-year withdrawal follow-up. Allergy. 2010;65:56-60.

29. Incorvaia C, Masieri S, Scurati S, Soffia S, Puccinelli P, Frati F. The current role of sublingual immunotherapy in the treatment of allergic rhinitis in adults and children. J Asthma Allergy. 2011;4:13-17.

30. Bahadori K, Quon BS, Doyle-Waters MM, Marra C, Fitzgerald JM. A systematic review of economic evaluations of therapy in asthma. J Asthma Allergy. 2010;3:33-42.

31. Campbell JD, Spackman DE, Sullivan SD. The costs and consequences of omalizumab in uncontrolled asthma from a USA payer perspective. Allergy. 2010;65:1141-1148.

32. Menzella F, Facciolongo N, Piro R, et al. Clinical and pharmacoeconomic aspects of omalizumab: a 4-year follow-up. Ther Adv Respir Dis. 2012;6:87-95.

33. van Nooten F, Stern S, Braunstahl GJ, Thompson C, Groot M, Brown RE. Cost-effectiveness of omalizumab for uncontrolled asthma in The Netherlands. J Med Econ. 2013;16:342-348.

34. Hoshino M, Ohtawa J. Effects of adding omalizumab, an anti-immunoglobulin e antibody, on airway wall thickening in asthma. Respiration. 2012;83:520-528.

35. Riccio AM, Dal Negro RW, Micheletto C, et al. Omalizumab modulates bronchial reticular basement membrane thickness and eosinophil infilitration in severe persistent allergic asthma patients. Int J Immunopathol Pharmacol. 2012;25:475-484.

36. Casale TB, Condemi J, LaForce C, et al. Effect of omalizumab on symptoms of seasonal allergic rhinitis: a randomized controlled trial. JAMA. 2001;286:2956-2967.

37. Chervinsly P, Casale T, Townley R, et al. Omalizumab, and anti-IgE antibody, in the treatment of adults and adolescents with perennial allergic rhinitis. Ann Allergy Asthma Immunol. 2003;91:160-167.

38. Humbert M, Boulet LP, Niven RM, Panahloo Z, Blogg M, Ayre G. Omalizumab therapy: patients who achieve greatest benefit for their asthma experience greatest benefit for rhinitis. Allergy. 2009;64: 81-84.

39. Verbruggen K, Van Cauwenberge P, Bachert C. Anti-IgE for the treatment of allergic rhinitis - and eventually nasal polyps? Int Arch Allergy Immunol. 2009;148:87-98.

40. Penn R, Mikula S. The role of anti-IgE immunoglobulin therapy in nasal polyposis: a pilot study. Am J Rhinol. 2007;21:428-432.

41. Bains SN, Judson MA. Allergic bronchopulmonary aspergillosis. Clin Chest Med. 2012;33:265-281.

42. ven der Ent CK, Hoekstra H, Rijkers GT. Successful treatment of allergic bronchopulmonary aspergillosis with recombinant anti-IgE antibody. Thorax. 2007;62:276-277. 
43. Kanu A, Patel K. Treatment of allergic bronchopulmonary aspergillosis (ABPA) with anti-IgE antibody (omalizumab). Pediatr Pulmonol. 2008:43:1249-1251.

44. Lebecque P, Leonard A, Argaz M, Godding V, Pilette C. Omalizumab for exacerbations of allergic bronchopulmonary aspergillosis in patients with cystic fibrosis. BMJ Case Rep. 2009;2009:pii: bcr07.2008.0379.

45. Lebecque P, Leonard A, Piletre C. Omalizumab for treatment of ABPA exacerbations in CF patients. Pediatr Pulmonol. 2009;44:516.

46. Collins J, Devos G, Hudes G, Rosenstreich D. Allergic bronchopulmonary aspergillosis treated successfully for one year with omalizumab. J Asthma Allergy. 2012;5:65-70.

47. Wong R, Wong M, Robinson PD, Fitzgerald DA. Omalizumab in the management of steroid dependent allergic bronchopulmonary aspergillosis (ABPA) complicating cystic fibrosis. Paediatr Respir Rev. 2013;14:22-24.

48. Incorvaia C, Mauro M, Riario-Sforza GG, Frati F, Tarantini F, Caserini M. Current and future applications of the anti-IgE antibody omalizumab. Biologics. 2008;2:67-73.

49. Sheinkopf LE, Rafi AW, Do LT, Katz RM, Klaustermeyer WB. Efficacy of omalizumab in the treatment of atopic dermatitis: a pilot study. Allergy Asthma Proc. 2008;29:530-537.

50. Heil PM, Maurer D, Klein B, Hultsch T, Stingl G. Omalizumab therapy in atopic dermatitis: depletion of $\operatorname{IgE}$ does not improve the clinical course - randomized, placebo-controlled and double-blind pilot study. J Dtsch Dermatol Ges. 2010;8:990-998.

51. Boyce JA. Successful treatment of cold-induced urticaria/anaphylaxis with anti-IgE. J Allergy Clin Immunol. 2006;117:1415-1418.

52. Bullerkotte U, Wieczorek D, Kapp A, Wedi B. Effective treatment of refractory severe heat urticaria with omalizumab. Allergy. 2010;65: 931-932.

53. Bindslev-Jensen C, Skov PS. Efficacy of omalizumab in delayed pressure urticaria: a case report. Allergy. 2010;65:138-139.

54. Güzelbey O, Ardelean E, Magerl M, Zuberbier T, Maurer M, Metz M. Successful treatment of solar urticaria with anti-immunoglobulin $\mathrm{E}$ therapy. Allergy. 2008;63:1563-1565.

55. Metz M, Bergmann P, Zuberbier T, Maurer M. Successful treatment of cholinergic urticaria with anti-immunoglobulin E therapy. Allergy. 2008;63:247-249.

56. Waibel KH, Reese DA, Hamilton RG, Devillez RL. Partial improvement of solar urticaria after omalizumab. J Allergy Clin Immunol. 2010;125: 490-491.

57. Sabroe RA. Failure of omalizumab in cholinergic urticaria. Clin Exp Dermatol. 2010;35:127-129.

58. Sands MF, Blume JW, Schwartz SA. Successful treatment of 3 patients with recurrent idiopathic angioedema with omalizumab. JAllergy Clin Immunol. 2007;120:979-981.

59. Spector SL, Tan RA. Effect of omalizumab on patients with chronic urticaria. Ann Allergy Asthma Immunol. 2007;99:190-193.

60. Kaplan AP, Joseph K, Maykut RJ, Geba GP, Zeldin RK. Treatment of chronic autoimmune urticaria with omalizumab. J Allergy Clin Immunol. 2008;122:569-573.

61. Maurer M, Rosen K, Hsieh HJ, et al. Omalizumab for the treatment of chronic idiopathic or spontaneous urticaria. N Engl J Med. 2013;368: 924-935.

62. Siebenhaar F, Kühn W, Zuberbier T, Maurer M. Successful treatment of cutaneous mastocytosis and Meniere disease with anti-IgE therapy. J Allergy Clin Immunol. 2007;120:213-215.

63. Carter MC, Robyn JA, Bressler PB, Walker JC, Shapiro GG, Metcalfe DD. Omalizumab for the treatment of unprovoked anaphylaxis in patients with systemic mastocytosis. J Allergy Clin Immunol. 2007;119: $1550-1551$.

64. Rueff F, Dugas-Breit S, Przybilla B. Stinging Hymenoptera and mastocytosis. Curr Opin Allergy Clin Immunol. 2009;9:338-342.

65. Kontou-Fili K, Fili CI. Prolonged high-dose omalizumab is required to control reactions to venom immunotherapy in mastocytosis. Allergy. 2009;64:1384-1385.
66. Douglass JA, Carroll K, Voskamp A, Bourke P, Wei A, O’Hehir RE. Omalizumab is effective in treating systemic mastocytosis in a non atopic patient. Allergy. 2010;65:926-927.

67. Bock SA, Munoz-Furlong A, Sampson HA. Fatalities due to anaphylactic reactions to foods. J Allergy Clin Immunol. 2001;107: 191-193.

68. Leung DY, Sampson HA, Yunginger JW, et al. Effects of anti-IgE therapy in patients with peanut allergy. $N$ Engl J Med. 2003;348:975-976.

69. Jones JD, Marney SR Jr, Fahrenholz JM. Idiopathic anaphylaxis successfully treated with omalizumab. Ann Allergy Asthma Immunol. 2008; 101:550-551.

70. Warrier P, Casale TB. Omalizumab in idiopathic anaphylaxis. Ann Allergy Asthma Immunol. 2009;102:257-258.

71. Bray SM, Fajt ML, Petrov AA. Successful treatment of exercise-induced anaphylaxis with omalizumab. Ann Allergy Asthma Immunol. 2012;109: 281-282.

72. Robson-Ansley P, Toit GD. Pathophysiology, diagnosis and management of exercise-induced anaphylaxis. Curr Opin Allergy Clin Immunol. 2010;10:312-317.

73. Rafi A, Do LT, Katz R, Sheinkopf LE, Simons CW, Klaustermeyer W. Effects of omalizumab in patients with food allergy. Allergy Asthma Proc. 2010;31:76-83.

74. Savage JH, Courneya JP, Sterba PM, Macglashan DW, Saini SS, Wood RA. Kinetics of mast cell, basophil, and oral food challenge responses in omalizumab-treated adults with peanut allergy. JAllergy Clin Immunol. 2012;130:1123-1129.

75. Foroughi S, Foster B, Kim N, et al. Anti-IgE treatment of eosinophilassociated gastrointestinal disorders. J Allergy Clin Immunol. 2007;120: 594-601.

76. Foster B, Foroughi S, Yin Y, Prussin C. Effect of anti-IgE therapy on food allergen specific $\mathrm{T}$ cell responses in eosinophil associated gastrointestinal disorders. Clin Mol Allergy. 2011;9:7.

77. Ridolo E, Montagni M, Olivieri E, Rogkakou A, De' Angelis GL, Canonica GW. Eosinophilic esophagitis: which role for food and inhalant allergens? Asia Pac Allergy. 2012;2:237-241.

78. Rocha R, Vitor AB, Trindade E, et al. Omalizumab in the treatment of eosinophilic esophagitis and food allergy. Eur J Pediatr. 2011;170: 1471-1474.

79. Cabanes N, Igea JM, de la Hoz B, et al. Latex allergy: position paper. J Investig Allergol Clin Immunol. 2012;22:313-330.

80. Leynadier F, Doudou O, Gaouar H, et al. Effect of omalizumab in health care workers with occupational latex allergy. J Allergy Clin Immunol. 2004;113:360-361.

81. Calonge M, Herreras JM. Clinical grading of atopic keratoconjunctivitis. Curr Opin Allergy Clin Immunol. 2007;7:442-445.

82. Williams PB, Sheppard JD Jr. Omalizumab: a future innovation for treatment of severe ocular allergy? Exp Opin Biol Ther. 2005;5: $1603-1609$.

83. Taillé C, Doan S, Neukirch C, Aubier M. Omalizumab for severe atopic keratoconjunctivitis. BMJ Case Rep. 2010;2010:pii: bcr0420102919.

84. Bard S, Paravisini A, Avilés-Izquierdo JA, Fernandez-Cruz E, SánchezRamón S. Eczematous dermatitis in the setting of hyper-IgE syndrome successfully treated with omalizumab. Arch Dermatol. 2008;144: $1662-1663$.

85. Lee J, Doggweiler-Wiygul R, Kim S, Hill BD, Yoo TJ. Is interstitial cystitis an allergic disorder? A case of interstitial cystitis treated successfully with anti-IgE. Int J Urol. 2006;13:631-634.

86. Fairley JA, Baum CL, Brandt DS, Messingham KA. Pathogenicity of IgE in autoimmunity: successful treatment of bullous pemphigoid with omalizumab. J Allergy Clin Immunol. 2009; 123:704-705.

87. Pinto JM, Mehta N, DiTineo M, Wang J, Baroody FM, Naclerio RM. A randomized, double-blind, placebo-controlled trial of anti-IgE for chronic rhinosinusitis. Rhinology. 2010;48:318-324.

88. Bobolea I, Barranco P, Fiandor A, Cabañas R, Quirce S. Omalizumab: a potential new therapeutic approach for aspirin-exacerbated respiratory disease. J Investig Allergol Clin Immunol. 2010;20:448-449. 
89. Parks KW, Casale TB. Anti-immunoglobulin E monoclonal antibody administered with immunotherapy. Allergy Asthma Proc. 2006; 27 Suppl 1:S33-S36.

90. Incorvaia C, Frati F, Puccinelli P, Riario-Sforza GG, Dal Bo S. Dose dependence of efficacy and safety of subcutaneous immunotherapy. Monaldi Arch Chest Dis. 2006;65:41-43.

91. Massanari M, Nelson H, Casale T, et al. Effect of pretreatment with omalizumab on the tolerability of specific immunotherapy in allergic asthma. J Allergy Clin Immunol. 2010;125:383-389.

92. Kamin W, Kopp MV, Erdnuess F, Schauer U, Zielen S, Wahn U. Safety of anti-IgE treatment with omalizumab in children with seasonal allergic rhinitis undergoing specific immunotherapy simultaneously. Pediatr Allergy Immunol. 2010;21:160-165.

93. Kopp MV, Hamelmann E, Zielen S, et al. Combination of omalizumab and specific immunotherapy is superior to immunotherapy in patients with seasonal allergic rhinoconjunctivitis and co-morbid seasonal allergic asthma. Clin Exp Allergy. 2009;39:271-279.

94. Müller UR, Helbling A, Berchtold E. Immunotherapy with honeybee venom and yellow jacket venom is different regarding efficacy and safety. J Allergy Clin Immunol. 1992;89:529-534.

95. Schulze J, Rose M, Zielen S. Beekeepers anaphylaxis: successful immunotherapy covered by omalizumab. Allergy. 2007;62:963-964.
96. Rerinck HC, Rueff F, Przybilla B. Recurrent severe anaphylactic reactions to venom immunotherapy (VIT): omalizumab induces tolerance. J Allergy Clin Immunol. 2008;Suppl 29:111.

97. Galera C, Soohun N, Zankar N, Caimmi S, Gallen C, Demoly P. Severe anaphylaxis to bee venom immunotherapy: efficacy of pretreatment and concurrent treatment with omalizumab. J Investig Allergol Clin Immunol. 2009;19:225-229.

98. Soriano Gomis V, Gonzalez Delgado P, Niveiro Hernandez E. Failure of omalizumab treatment after recurrent systemic reactions to beevenom immunotherapy. J Investig Allergol Clin Immunol. 2008;18: 225-226.

99. Kopp MV. Omalizumab: and anti-IgE therapy in allergy. Curr Allergy Asthma Rep. 2011;11:101-116.

100. Sanchez J, Ramirez R, Diez S, et al. Omalizumab beyond asthma. Allergol Immunopathol (Madr). 2012;40:306-315.

101. Babu KS, Polosa R, Morjaria JB. Anti-IgE - emerging opportunities for omalizumab. Expert Opin Biol Ther. 2013;13:765-777.

102. Shankar T, Petrov AA. Omalizumab and hypersensitivity reactions. Curr Opin Allergy Clin Immunol. 2013;13:19-24.

\section{Publish your work in this journal}

Drug Design, Development and Therapy is an international, peerreviewed open-access journal that spans the spectrum of drug design and development through to clinical applications. Clinical outcomes, patient safety, and programs for the development and effective, safe, and sustained use of medicines are a feature of the journal, which

\section{Dovepress}

has also been accepted for indexing on PubMed Central. The manuscript management system is completely online and includes a very quick and fair peer-review system, which is all easy to use. Visit http://www.dovepress.com/testimonials.php to read real quotes from published authors

Submit your manuscript here: http://www.dovepress.com/drug-design-development-and-therapy-journal 